\title{
The Silent Content of Bound Variable Pronouns*
}

\author{
Uli Sauerland \\ Universität Tübingen
}

\begin{abstract}
Bound variable pronouns are usually understood to be interpreted as bound variables. This paper argues that bound variable pronouns have an internal property argument $P$ and that $P$ is interpreted as a presupposition on the value of the bound variable pronoun. The argument leading to these conclusions proceeds through the following intermediate theses, which are of independent interest: 1) bound variable pronouns can differ in interpretation, 2) indexation alone is insufficient to explain the way bound variable pronouns differ, 3) bound variable pronouns can have a presupposition, 4) in general, the silent content
\end{abstract}

\footnotetext{
*Thanks to Elena Anagnostopoulou, Danny Fox, Irene Heim, Hans Kamp, Graham Katz, Winfried Lechner, Pauline Jacobson, Peter Krause, Orin Percus, Wolfgang Sternefeld, and Kazuko Yatsushiro for their comments. I presented an earlier version of this paper at SALT 10 at Cornell University, and parts of this version are based on my paper in the proceedings of that conference (Sauerland 2000), while others substantially deviate from that version. This paper was written at Tsukuba University in April 2002 and I would like to express my thanks to Hidekazu Suzuki and Tsutomu Yatsushiro for their hospitality.
}

final version to appear in: Kyle Johnson (ed.) Topics in Ellipsis. Oxford University Press.

printed on April 19, 2004 
must be a silent property variable internal to the bound variable pronoun, rather than being an elided syntactic representation.

When I confronted a certain non-linguist I know with a sentence like (1), she voiced the opinion that the pronoun his refers to the set of boys. Of course, I quickly showed her that this can't be because (1) doesn't mean the same as every boy likes the mother of the boys, and went on to tell her that a genuinely new concept like that of a bound variable is required to analyze the contribution of his to the meaning of (1).

(1) Every boy likes his mother.

My non-linguist friend, however, may easily be forgiven, given that it took Frege's (1879) ingenuity to come up with the concept of a bound variable which led to a successful analysis of sentences like (1)and that Frege's insights are not well known in the general population. In this paper, I address a puzzling phenomenon that will give us another reason to forgive the mistake of my non-linguist friend. This phenomenon, focus on bound pronouns, came to my attention some years ago, and I will argue that its analysis requires an appeal to precisely what my non-linguist friend took to be the reference of the pronoun in (1). I'll argue that this pronoun can contain in it a silent reference to the set of boys. Once I've defended my non-linguist friend in this way, I'll go on make this paper relevant to this volume by considering the question of whether this silent content is silenced by ellipsis or silent for some other reason. 
More prosaically, the structure of my paper is described as follows: In section 1, I introduce the phenomenon of focus on bound pronouns and some background assumptions of focus semantics to argue that bound pronouns differ in meaning. In section 2, I consider and reject the possibility of accounting for these facts solely within the standard analysis of bound variable pronouns as indexed variables. In section 3, I argue for an analysis of the phenomena in question, making use of the idea that the bound variable pronoun is a bound definite description with its range as presuppositional content. In section 4, I consider the possibilities of accounting for the silence of this presuppositional content, namely an ellipsis analysis or silent property variable, and argue for the latter. Section 5 is the conclusion.

\section{Bound Pronouns can Differ in Meaning}

Consider the two sentences in (2). The salient interpretation is one where both occurrences of the pronoun his are interpreted as bound variable pronouns bound by the subject quantifier of their respective sentence.

(2) Every boy called his mother. Every TEACHER, on the other hand, called HIS mother.

Note that the second occurrence of his in (2) must be focussed. In (2) and in the following, narrow focus on one word is indicated by capitalization of that word. Such 
focus on a bound variable pronoun is my primary interest in this paper. In most cases, this focus is optional and I used a trick to make it obligatory in (2): It's easy to see that the focus in (2) is obligatory because of the presence of on the other hand, and, if we leave this out, the focus becomes optional.

It's well known that focus is intimately connected with the meaning of constituents. Indeed, focus is as important as it is in current semantic theorizing because it provides a way to test for the meaning of constituents that's independent of sentence meaning and a theory of composition. The examples in (3) are just a simple illustration of the generalization that focus is placed on that part/those parts of a sentence that plausibly differ in meaning from a relevant antecedent sentence.

(3) a. On Monday, Bob called Mary. On TUESday, JIM called HER. 'Her' cannot be Mary.

b. On Monday, Bob called Mary. On TUESday, JIM called her. 'Her' must be Mary.

From this perspective, example (2) suggests that two occurrences of a bound variable pronoun can differ in meaning. To argue that this is indeed true, I'll now adopt a precise theory of focus licensing, namely that of Schwarzschild (1999). I briefly summarize the consequences of this theory my research relies on, and then I return to the question of focus on bound variable pronouns. 
DRAFT

\subsection{The Licensing of Focus}

Schwarzschild (1999) develops a theory of focus licensing that has been widely accepted. Because the theory is quite intricate, I want to make use of a modified, simpler version of it in the following. This version will yield the same result for the cases relevant in this paper.

The idea of Schwarzschild's (1999) proposal is that focus is licensed by competition. This competition generally seeks to avoid focus. Therefore focus is only licensed if none of the competitors considered by the licensing system has less focus. For example, the fact that the focussed her in (4) cannot refer to Mary, as we observed in (3a) this competition provides the following explanation: if her did refer to Mary, it would be possible to not focus her, as we saw in (3b). Therefore, focus in (4a) isn't licensed if we assume that the representation of (3b) is a competitor.

(4) On Monday, Bob called Mary. On TUESday, JIM called HER.

Furthermore, the above reasoning doesn't apply if her doesn't refer to Mary, but to someone else. Since the focus can't be omitted in that case, the focus is licensed in (4). In this way, Schwarzschild's general idea provides an account for the facts in (3) and (4).

The account relies on a concept of a reference set, just like all other mechanisms that appeal to competition amongst candidates. Schwarzschild's proposal relies on a 
very broadly defined reference set, and motivates this proposal in his paper. However, this proposal is very unwieldy in a practical case since so many possibilities need to be considered. Therefore, I take the liberty of adopting for this paper the corollary of Schwarzschild's account in (5); furthermore, I'll still call this Schwarzschild's account. ${ }^{1}$

(5) A focus on an XP that is asymmetrically dominated by a non-focussed phrase is licensed only if there is a Focus Domain constituent FD asymmetrically dominating XP such that for a Focus Antecedent constituent FA in the preceding discourse (or entailed by it) the following two conditions are satisfied:

a. Givenness: $\llbracket \mathrm{FA} \rrbracket \in \llbracket \mathrm{FD} \rrbracket_{\text {f }}$. (I.e. there is a Focus-Alternative $\mathrm{FD}^{\prime}$ of $\mathrm{FD}$ with $\left.\llbracket \mathrm{FA} \rrbracket=\llbracket \mathrm{FD}^{\prime} \rrbracket\right)$

b. Contrastiveness: $\llbracket \mathrm{FA} \rrbracket \notin \llbracket \mathrm{FD}^{-} \rrbracket$ , where $\mathrm{FD}^{-}$is identical to $\mathrm{FD}$, except that XP isn't focussed in $\mathrm{FD}^{-}$.

Condition (5) is easy to apply since it involves only one competitor, $\mathrm{FD}^{-}$. In fact, in the case considered above, $\mathrm{FD}^{-}$is precisely the sentence without focus on the pronoun. The informal reasoning given above can now be reconstructed as in (6). The focus antecedent could be the preceding clause as in (6a). To verify that (6b) is then a focus domain that satisfies the givenness clause (5a), consider that the $\mathrm{FD}^{\prime}$ in

${ }^{1}$ Cf. Rooth's (1992a) Focus Interpretation Principle or Schwarzschild's (1999) Givenness with (5a), Schwarzschild's (1999) Avoid F with (5b). 
(6c) is a focus alternative of (6b). Now consider the contrastiveness condition (5b). The relevant $\mathrm{FD}^{-}$is shown in (6d). It's easy to see that in this case $\llbracket \mathrm{FA} \rrbracket$ is not a focus alternative of $\mathrm{FD}^{-}$.

(6) $\quad$ FA $=$ Bob called Maryi

b. $\quad \mathrm{FD}=[\mathrm{JIM}]_{\mathrm{F}}$ called $\left[\mathrm{HER}_{\mathrm{j}}\right]_{\mathrm{F}}$

c. $\quad \mathrm{FD}^{\prime}=$ Bob called Mary

d. $\quad \mathrm{FD}^{-}=[\mathrm{Jim}]_{\mathrm{F}}$ called her

Note, furthermore, that the reasoning we just went through relied on the fact that her and Mary aren't coreferent. If they were coreferent, the meaning of the focus antecedent (6a) would be a focus alternative of $\mathrm{FD}^{-}$, and therefore this choice of focus domain wouldn't be sufficient to license the focus on the pronoun. But for other choices of the focus domain, it follows in an analogous way that focus on the pronoun cannot be licensed, and therefore we have convinced ourselves that indeed the focus cannot be licensed when her and Mary are coreferent.

\subsection{The Meaning of Bound Variable Pronouns}

Now consider again examples like (2) with focus on a bound pronoun.

(7) Every boy called his mother. Every TEACHER, on the other hand, called HIS mother. 
As I mentioned above, the use of on the other hand in (7) makes the focus on the bound pronoun his obligatory. This served to make the empirical point more clearly, however, for the analysis of such examples provides additional difficulties. I'll return to the analysis of adversative focus particles in the next section, but first consider example (8). In this example, the focus on the bound pronoun is optionally possible. Intuitively, the focus seems to involve a contrast between his in the discourse and the focussed his.

(8) Discourse: On Monday, every boy called his mother.

a. On TUESday, every TEAcher called HIS mother.

How, then, is the focus in (8a) licensed? I'll now show that it follows from the focus licensing condition adopted in the previous chapter, that the contributions the two bound pronouns in (8) make to the meaning of their sentences must be different.

To show this, all possible choices of FA and FD must be looked at to verify that focus on $H I S$ is only licensed if $H I S$ and his differ in interpretation. I'll actually consider only two exemplary cases of FA and FD. First, I look in (9) at FA and FD that don't include the binders, then in (10) at FA and FD that include the binders of the two pronouns.

(9) $\quad$ a. $\quad \mathrm{FA}=$ his mother

b. $\quad \mathrm{FD}=[\mathrm{HIS}]_{\mathrm{F}}$ mother 
c. $\quad \mathrm{FD}^{\prime}=$ Mary's mother

d. $\quad \mathrm{FD}^{-}=$his mother

For the FA and FD in (9), contrastiveness requires that $\llbracket \mathrm{FA} \rrbracket \notin \llbracket \mathrm{FD}^{-} \rrbracket_{\mathrm{f}}$, and this entails that $\llbracket$ his mother $\rrbracket \neq \llbracket$ his mother $\rrbracket$, which seems like a contradiction since silent content isn't represented. This can only be satisfied if the occurrence of his in FA and that in $\mathrm{FD}^{-}$have different interpretations.

Secondly, consider FA and FD in (10), which include the binder.

(10) $\quad$ a. $\quad F A=$ Every boy called his mother.

b. $\quad \mathrm{FD}=$ Every $[\text { TEAcher }]_{\mathrm{F}}$ called $[\mathrm{HIS}]_{\mathrm{F}}$ mother

c. $\quad \mathrm{FD}^{\prime}=$ Every boy called his mother

d. $\quad \mathrm{FD}^{-}=$Every $[\text {teacher }]_{\mathrm{F}}$ called his mother

Contrastiveness requires that the focus alternative $\mathrm{FD}^{-\prime}$ of $\mathrm{FD}^{-}$shown in (11) differ in interpretation from FA. Again, the occurrences of his in (11) must somehow have different interpretations for (11) to be true.

(11) $\llbracket \mathrm{FD}^{-\prime} \rrbracket=\llbracket$ Every boy called his mother $\rrbracket \neq \llbracket$ Every boy called his mother $\rrbracket=$ $\llbracket \mathrm{FA} \rrbracket$ 
In this way, Schwarzschild's proposal for the licensing of focus implies the conclusion that bound pronouns are ambiguous in a way not evident from their segmental phonology.

One might be tempted to propose a different explanation for the above facts. Namely, one might conclude that Schwarzschild's theory of focus licensing should be dismissed. However, the difficulties in formulating such an approach seem to me to be substantial. Consider two ideas that come to mind here, but which I believe are quite immediately seen to be flawed: One idea takes feature agreement in variable binding to be the source of the focus features on bound variables, while the other idea assumes that the focus licensing takes into account a representation where a quantified statement is reduced to one not containing any quantifiers.

Consider first the idea that feature agreement in variable binding is the source of the focus in (8). It's well known that bound variable pronouns agree in number, person, and gender with their antecedents. Example (12) illustrates number agreement on the pronoun they.

(12) The participants in the chess tournament all believe that they will win.

The natural interpretation of (12) is that each participant of the chess tournament believes that there'll only be a single winner, namely himself. However, this must be obligatorily expressed as in (12) by the use of the plural pronoun. This follows from 
the assumption that the bound variable pronoun must exhibit agreement in number with the matrix subject.

For (8), the idea would then be to say that focus on the pronoun can be inherited by some form of agreement with the antecedent similar to what is assumed in (12). This intuition is drawn from the observation that at least parts of the antecedent of the pronoun in $(8 \mathrm{a})$ are focussed. However, there are numerous problems with this idea. Consider only the case in (13). Here, the agreement idea predicts too many antecedents to be possible for the focussed pronoun: Both QPs, every boy and every teacher in (13) are equal in their focus structure. Nevertheless, only the latter QP can be the antecedent of the focussed pronoun HIS in (13).

(13) *Every BOY ${ }_{i}$ called his ${ }_{i}$ mother before every TEAcher $_{j}$ called HIS $_{i}$ mother.

Other problems with the agreement idea are that the focus on the antecedent can be deeply embedded in difference to the agreement feature, and that the focus is only optional while agreement is obligatory.

Now consider the second idea, that focus licensing in (8) makes reference to representations that don't contain any quantifiers. The idea would be that representations like (14) would exist for the sentences of (8) at this level.

(14) a. Student A called student A's mother, and student B called student B's mother, and ... 
b. Teacher A called teacher A's mother, and teacher B called teacher B's mother, and ...

While it may be possible to work out a proposal along these lines, one problem that would need to be addressed and which I don't know how to address, arises with sentences like (15).

(15) John ate a banana, and Bill ate a banana.

Example (16a) evokes a scenario where two different bananas, banana A and banana B, are involved. Hence, a quantifier free representation of (15) in this scenario might be (16).

(16) John ate banana A, and Bill ate banana B.

But then it's not clear why focussing the second occurrence of banana in (15) has the special effect it has. Namely with such a focus, one is forced to assume that there are two different concepts of banana. This is a fairly marked interpretation in (15), but it does have natural uses, as in (17).

(17) There are books, and there are BOOKS. 
One natural interpretation of (17) can be paraphrased as stating that there are 1) groupings of printed pages with a cover around and 2) objects that will change your, the reader's, life with the wealth of wisdom they reveal. This interpretation seems to involve two concepts of book, and this is licensing the focus on the second occurrence of books in (17). If we put aside this phenomenon, (15) doesn't allow focus, and the idea of licensing focus by reduction to some quantifier free form would need to explain why this is the case.

Unless these problems can somehow be overcome, what we're left with seems to be the conclusion that occurrences of bound variable pronouns must be allowed to differ in their interpretation. In contrast to most other cases of focus, this difference in interpretation isn't evident from their segmental phonology.

\subsection{Some Applications}

The result of the previous section has some interesting applications. One is that it can be used to test whether an expression is a bound variable or not. This is of particular interest in the case of complex anaphoric expressions the internal composition of which is opaque.

Consider the contrast in (18) (Jacobson 2000 gives similar examples). The optional focus on a bound variable pronoun, in the case of the English reflexive himself, must be located on the pronominal part. 
(18) a. John likes himself and Bill likes HIMself.

b. *John likes himself and Bill likes himSELF.

Observe that in principle the self part can also bear focus, as shown in (19). Therefore, the contrast in (18) corroborates that idea that the English reflexive is semantically a complex expression consisting of a bound variable pronoun and a reflexivizer self that underlies, for example, the analysis by Reinhart and Reuland (1993).

(19) John likes Mary, but Bill likes himSELF.

Consider, furthermore, the reflexive sich of German. Sich can be optionally focussed in (20). Since there is an antecedent with the same lexical VP available in (19), I conclude that the focus on sich is licensed only because sich is interpreted as a bound variable.

(20) Die Michaela hat sich für den Posten vorgeschlagen, und die TANJA hat the Michaela has self for the office proposed, and the Tanja has SICH vorgeschlagen.

self proposed

Furthermore, there's a contrast between (20) and example (21), where sich is the internal argument of the inherently reflexive verb ergeben (to surrender).

(21) \#Die Michaela hat sich ergeben, und die TANJA hat SICH ergeben. the Michaela has self surrendered, and the Tanja has self surrendered 
These observations corroborate the claim that sich is interpreted as a bound variable in (20), but not in the inherently reflexive (21) (Reinhart and Reuland 1993).

Finally, take a look at reciprocals. Neither the English examples in (22) nor the German examples in (23) allow the reciprocal to bear focus.

(22) * John and Mary like each other. Sue and Bill, however, like EACH other/each OTHER/ONE another/one ANOTHER.

(23) *Michaela und Tanja haben einander vorgeschlagen. Peter und Dieter Michaela and Tanja have each other proposed. Peter and Dieter (hingegen) haben EINander/einANDER vorgeschlagen. (however) have EACH other/each OTHER proposed

Therefore, we can conclude that neither English each other and one another nor German einander have overt parts that are interpreted as bound variables. This seems to mesh well with analyses like Roberts (1991), where the reciprocal is analyzed as having a complex semantic structure that contains only silent bound variables.

A nice contrast to (23) is (24), which doesn't contain the reciprocal, but rather the reflexive sich that is compatible with a reciprocal interpretation. In fact, the reciprocal interpretation is forced in (24) by use of the adverbial gegenseitig (mutually).

(24) Michaela und Tanja haben sich gegenseitig vorgeschlagen. Peter und Dieter Michaela and Tanja have self mutually proposed. Peter and Dieter (hingegen) haben SICH gegenseitig vorgeschlagen. (however) have SELF mutually proposed 
A second application of the result is that it provides an explanation of facts observed by Hirschberg and Ward (1991). Their experimental finding is that the strict/sloppy ambiguity of pronouns in ellipsis is disambiguated by the presence or absence of a focus on the pronoun in the antecedent of ellipsis. Hence, they predict a preference for the sloppy interpretation in $(25 \mathrm{a})$ and a preference for the strict interpretation in (25b).

a. John likes HIS mother and Bill does too. [sloppy reading preferred]

b. John likes his mother and Bill does too. [strict reading preferred]

Hirschberg and Ward's (1991) observation can be seen to largely follow from the observation that bound pronouns can differ in their interpretation. Note that this generalization predicts that, while (26) doesn't allow interpretation (26a) with coreferent pronouns, it does allow interpretation (26b) with variable binding.

(26) John likes his mother and Bill likes HIS mother.

a. ${ }^{*} \mathrm{John}_{\mathrm{j}}$ likes his $\mathrm{j}_{\mathrm{j}}$ mother and Bill likes his $\mathrm{j}_{\mathrm{j}}$ mother.

b. John $_{\mathrm{j}} \lambda_{i} i$ likes his $\mathrm{i}_{\mathrm{i}}$ mother and Bill $\lambda_{i} i$ likes $i$ mother

Therefore, I conclude that in (25a), too, the focus on the pronoun can only be licensed if both conjuncts contain a bound variable pronoun. The only difference between (25a) and (26) would then be that the order of conjuncts is the opposite, but we 
can assume that in this case the antecedent for focus licensing is accommodated. But then it follows that (25a) allows only the sloppy interpretation. This account still predicts that both the strict and the sloppy interpretation should be available for (25b). Potentially, though the observed effect in (25b) results from the setup of Hirschberg and Ward's (1991) experiment, where subjects were specifically asked to disambiguate between the strict and sloppy interpretation, it is natural to speculate that in this scenario the absence of a cue disambiguating in one direction is taken as evidence for the opposite disambiguation. In this way, the disambiguation observed in (25) could be entirely explained as resulting from the observation that bound variables can be contrasted.

\section{Indices and Focus}

Standardly, occurrences of bound variable pronouns are taken to differ only in the indices they bear. It seems natural to to make use of this difference to explain the focussability of bound variable pronouns (cf. Sauerland 1998, 1999). Consider the representation of (8) with indices, given in (27).

Discourse: On Monday, every boy $\lambda_{1} t_{1}$ called his mother $_{1}$

a. On TUESday, every TEAcher $\lambda_{2} t_{2}$ called $\mathrm{HIS}_{2}$ mother 
The indexation shown in (27) could be sufficient to license focus if focus licensing applies to constituents in which the bound variable pronouns aren't bound. Recall that Rooth (1992a) has already shown that the focus licensing conditions can apply sentence internally in examples like An AMERICAN farmer talked to a CANADIAN farmer. Specifically, for the choices of focus domain and antecedent in (28), the contrastiveness condition seems to be satisfied. The requirement imposed by contrastiveness for $(28)$ is that $\llbracket F A \rrbracket \neq \llbracket \mathrm{FD}^{-} \rrbracket$, which indeed holds for certain assignments.

(28) a. FA $=$ his $_{1}$ mother

b. $\quad \mathrm{FD}=\left[\mathrm{HIS}_{2}\right]_{\mathrm{F}}$ mother

c. $\quad \mathrm{FD}^{\prime}=$ his $_{1}$ mother

d. $\quad \mathrm{FD}^{-}=\mathrm{his}_{2}$ mother $\Longrightarrow \exists \mathrm{g}: \llbracket \mathrm{FA} \rrbracket^{g} \neq \llbracket \mathrm{FD}^{-} \rrbracket^{g}$

Contrastiveness as stated in (5b) above cannot be applied to (28) since FA and FDboth contain an unbound variable. A restatement of contrastiveness could in fact be done in such a way as either to make the resulting condition sensitive to differences in indexation, as in (29) or to make it not sensitive to such differences. Since the focus in (8) is licensed (see the account presented in Sauerland $(1998,1999)$ ), the statement (29a) must be adopted. Then contrastiveness is satisfied in (28) because, for any $g$ with different results for 1 and $2, \llbracket \mathrm{FA} \rrbracket^{g} \neq \llbracket \mathrm{FDs} \rrbracket^{g}$

(29) a. Contrastiveness (index-sensitive): for all Focus Alternatives $\mathrm{FD}^{-1}$ of $\mathrm{FD}^{-}$ there is an assignment $g$ such that $\llbracket \mathrm{FA} \rrbracket^{g} \neq \llbracket \mathrm{FD}^{-\prime} \rrbracket^{g}$ 
b. Contrastiveness (index-insensitive): for all Focus Alternatives $\mathrm{FD}^{-\prime}$ of $\mathrm{FD}^{-}$and for every assignment $g: \llbracket \mathrm{FA} \rrbracket^{g} \neq \llbracket \mathrm{FD}^{-\prime} \rrbracket^{g}$

Independent evidence for favoring condition (29a) over (29b) comes from cases with focus on unbound pronouns (cf. Rooth (1992b)). In example (30), focus on the second occurrence of him is required unless it refers to the same individual as the first occurrence of him. In (30), non-coreference is indicated by contra-indexation.

(30) Isabelle knows himi . But she doesn't know HIM

The index-insensitive condition (30b) would wrongly predict that focus on the second occurrence of him should not be licensed, because any focus domain containing this pronoun will be identical in meaning to the corresponding antecedent under an assignment that assigns the same value to $i$ and $j$.

\subsection{One Problem: Adnominal "however" and "too"}

There are problems in trying to reduce all cases of focus on bound pronouns to indexation. The problem shown in this section is related to a basic property of indexed variables - the fact that two representations that are identical except for the index of a variable binder and all variables bound by it don't differ in interpretation. In this situation, the two representations are called alphabetic variants of one another. The effect of alphabetic variants can be illustrated for (27) by considering the FA and FD 
in (31), which include the binders of the two pronouns. For (31), the focus licensing conditions are not satisfied (cf. Rooth 1992b) because FA and $\mathrm{FD}^{-}$are alphabetic variants and therefore don't differ in interpretation.

(31) a. $\mathrm{FA}=\lambda_{1} t_{1}$ called his ${ }_{1}$ mother

b. $\quad \mathrm{FD}=\lambda_{2} t_{2}$ called $\left[\mathrm{HIS}_{2}\right]_{\mathrm{F}}$ mother

c. $\quad \mathrm{FD}^{\prime}=\lambda_{2} t_{2}$ called his 2 mother

d. $\quad \mathrm{FD}^{-}=\lambda_{2} t_{2}$ called his $\mathrm{s}_{2}$ mother $\Longrightarrow \llbracket \mathrm{FA} \rrbracket=\llbracket \mathrm{FD}^{-} \rrbracket \# \#$

The equivalence of alphabetic variants predicts, therefore, that two occurrences of bound variables shouldn't be able to contrast when the compared constituents include their binders. This prediction can be tested if there are means to control for the size of the compared constituents. I think that the focus sensitive particles however and too (as well as many similar expressions) provide these means, in particular the adnominal variants of these.

As far as I know, no descriptive work on however has been done, but its essential properties can be captured quite easily. Consider the paradigm in (32): Adnominal however construed with the subject presupposes that both the subject 
and the VP differ in meaning with an antecedent. ${ }^{2,3}$

(32) Discourse: Carl called Mary.
a. JOHN, however, WROTE Mary.
b. JOHN, however, called BERta
c. \#JOHN, however, called Mary.
d. \#Carl, however, called BERta.

The contrasts of acceptability in (32) can be captured as a presupposition of however. For example, (32b) seems to have the presuppositions that there are $X$ and $Y$ such that a) $X$ called $Y$, b) $X$ didn't call Berta, and c) John didn't call $Y$. Given the

\footnotetext{
${ }^{2}$ As pointed out to me by Mats Rooth (p.c.) and Marga Reis (p.c.), however allows most easily a hat intonation of the type discussed by Büring (1995) among others. As far as I can see, however, my argument isn't affected by the difference between hat intonation and a double focus intonation. Therefore, I don't distinguish between the two intonations in the text.

${ }^{3}$ An interesting puzzle is that, when adjoined to a sentence, however requires only one contrast, as shown by (i) in contrast to (32d). I have at present no idea how to relate these two uses of however. For some speakers of English, (32d) is marginally acceptable - I assume that they can left-adjoin however to VP, rather than having to left adjoin it to the subject NP. In German examples with hingegen ('however') this VP-adjunction analysis can be controlled for because of the verb-second property. The English facts in the text can all be reproduced in German.
}

(i) However, Carl called BERta. 
discourse in (32) the presupposition is fulfilled with $X=$ Carl and $Y=$ Mary. Generalizing this picture a little, I propose that the presupposition for adnominal however is the following:

(33) 【[NP however $] \mathrm{VP} \rrbracket$ presupposes that there are focus alternatives $\mathrm{NP}^{\prime}$ and $\mathrm{VP}^{\prime}$ of NP and VP respectively such that:
a. $\llbracket \mathrm{NP}^{\prime} \mathrm{VP}^{\prime} \rrbracket=1$,
b. $\quad \llbracket \mathrm{NP}^{\prime} \mathrm{VP} \rrbracket=0$, and
c. $\quad \llbracket \mathrm{NP}^{\mathrm{VP}} \rrbracket=0$.

The argument in the following is now based on the observation that (34a) is acceptable, where however is attached to the antecedent of the bound pronoun and the bound pronoun intuitively is contrasted with another occurrence of a bound pronoun in the discourse. As the unacceptability of (34b) without focus on the bound pronoun shows, the focus on the bound pronoun satisfies the presupposition of however.

(34) Discourse: Every teacher believes that she'll win.
a. Every GIRL, however, believes that SHE'll win.
b. \#Every GIRL, however, believes that she'll win.

It turns out that the fact in (34) isn't predicted on the index based account of focus on bound pronouns. The indexed representation of (34a) is (35a). The focus alternatives 
licensing however should be the $\mathrm{NP}^{\prime}$ in $(35 \mathrm{~b})$ and for the VP, I consider the two possibilities in (35c) and (35d) - it's not clear whether $\mathrm{VP}^{\prime \prime}$ should be available as a focus alternative, but I consider it here just for argument's sake.

(35) a. [NP every GIRL] however [vP $\lambda_{2} t_{2}$ believes that $\mathrm{SHE}_{2}{ }^{\prime} l l$ win.]

b. $\quad \mathrm{NP}^{\prime}=$ every teacher

c. $\mathrm{VP}^{\prime}=\lambda_{2} t_{2}$ believes that she ${ }_{1}^{\prime}$ 'll win.

d. $\quad \mathrm{VP}^{\prime \prime}=\lambda_{1} t_{1}$ believes that she ${ }_{1}^{\prime}$ 'll win.

For $\mathrm{NP}^{\prime}$ and $\mathrm{VP}^{\prime}$, none of the focus licensing conditions are satisfied in the discourse in (33): Since $s^{2} e_{1}$ is an unbound variable, in (35c) the satisfaction of the three licensing conditions is not affected by the presence of the discourse antecedent in (34), but rather depends on what the assignment assigns to index 1 . This is clearly not the desired result. The focus licensing conditions are also not satisfied for VP" in (35d): Since $\mathrm{VP}^{\prime \prime}$ and VP are alphabetic variants, the presuppositions (33b) and (33c) of however aren't satisfied for $\mathrm{NP}^{\prime}$ and $\mathrm{VP}^{\prime \prime}$. Therefore, the incorrect prediction made by the index based account is that (34a) should be just as unacceptable as (34b).

An argument similar to the one with however can be made with adnominal too. There is some descriptive work on too and words with similar meaning in general, but I don't know of any work addressing specifically the adnominal use of too illustrated in 
(36). Adnominal too seems to presuppose that for a focus alternative to the subject, the VP is true.

(36) Discourse: Carl visited Mary.

a. JOHN, too, visited Mary.

b. ${ }^{*} \mathrm{JOHN}$, too, visited BERta.

Applying Soames's (1989) insights on the semantics of too to the adnominal case, I propose the semantics in (37).

(37) 【NP too $\mathrm{VP} \rrbracket$ presupposes that there is a focus alternative $\mathrm{NP}^{\prime}$ of $\mathrm{NP}$ such that a. $\llbracket \mathrm{NP}^{\prime} \mathrm{VP} \rrbracket=1$.

Consider now the example in (38), which combines adnominal too with variable binding. As (38b) shows, the presence of too doesn't allow the bound variable to be focussed.

(38) Discourse: Every teacher believes that she'll win.

a. Every GIRL, too, believes that she'll win.

b. \#Every GIRL, too, believes that SHE'll win. 
The oddness of (38b) is not predicted by the index based account of focus in such examples. Specifically, the indexed representation in (39) shows that the VP here is predicted to be true of the $\mathrm{NP}^{\prime}$ every teacher, and therefore the presupposition of too should be fulfilled in (38b).

(39) [NP every GIRL] too [vP $\lambda_{2} t_{2}$ believes that $\mathrm{SHE}_{2}$ 'll win]

In summary, this section has showed a number of points. The main focus has been to argue that different indices alone are insufficient to explain the focussability of bound variables. In addition to this negative result, we have also improved our working description of the phenomena over that of the previous section. In the previous section, I showed that two occurrences of a bound pronoun can differ in meaning. In this section, I have showed that the difference in meaning between two bound pronouns can be such that even otherwise identical constituents in which the bound variables are bound differ in interpretation. Because of this, indexation alone cannot explain the focussability of bound pronouns, and in the next section I'll argue for a new account based on the idea that the bound pronouns have presuppositional content. 


\section{Bound Pronouns have Content}

The new account I argue for in this section assumes that bound variable pronouns have actual semantic content in addition to the variable index. This content must be interpreted as a presupposition of the bound variable. There are two closely related intuitions as to how we can understand such constructions.

One intuition is based on the observation that bound variable pronouns actually can have some overt semantic content, namely person, gender, and number marking. This content is actually interpreted (at least in many cases), as example (40) illustrates. The feminine marking on she in (40) has the effect that (40) is understood as a generalization about female teachers.

(40) Every teacher thinks she female $_{\text {is }}$ brilliant.

Following Cooper (1979) and others, I assume that the content of the bound pronoun is interpreted as yielding a presupposition on the denotation of the bound variable. An interpretation rule to this effect is (41).

(41) $\llbracket$ pro $_{\mathrm{i}} \mathrm{P} \rrbracket^{g}$ presupposes that $P(g(i))=1$.

When defined: $\llbracket p r o_{\mathrm{i}} \mathrm{P} \rrbracket^{g}=g(i)$

In (40) the feature feminine is interpreted by (41) as leading to a presupposition that $g(i)$ be feminine. Following what is known about presupposition projection from the 
scope of universal quantifiers (Heim 1983 and others) this predicts that (40) has a presupposition that all teachers are female. My claim is that not only overtly realized features such as feminine in (40), but also other presuppositional content can occur with bound variables.

A slightly different intuition starts from the claim originally due to Evans (1977) that some occurrences of pronouns can be hidden definite descriptions. These are the so-called E-type pronouns. We may ask whether even bound variable pronouns may be E-type pronouns as well. This would require us to assume an interpretation rule for bound definite descriptions such as (42).

【 the $\mathrm{i}_{\mathrm{i}} \mathrm{P} \rrbracket^{g}$ presupposes that $\mathrm{P}(g(i))=1$.

When defined $\llbracket$ the $\mathrm{e}_{\mathrm{i}} \mathrm{P} \rrbracket^{g}=g(i)$

From the way I have presented the two interpretation rules (41) and (42), it's evident that the two lead to same result. Hence, I'll consider these two approaches as equivalent in the following. For concreteness, I adopt (42) as notation in the following, and I'll use the term bound E-type pronoun to refer to this representation.

Obviously, an important question is to characterize what exactly the unpronounced presupposition can be that must always be satisfied, since it could never be accommodated successfully. For the discussion in the following, I start with the assumption that the restrictor of the antecedent is identical to the content of the 
bound pronoun. As we'll see, however, it will be necessary to adjust this assumption and to allow any presupposition that is satisfied in the interpretation of the sentence within the current discourse context.

\subsection{Account of Focus Licensing}

How does the assumption that bound pronouns can have semantic content explain the possibility of focus on a bound pronoun? Consider again (43) (repeated from (8)) with focus on the bound pronoun.

(43) Discourse: On Monday, every boy called his mother.

a. On TUESday, every TEAcher called HIS mother.

The new account allows the representations in (44) where both bound pronounsthat in the discourse antecedent and that in target sentence - are bound definite descriptions.

(44) Discourse: every boy $\lambda_{1} t_{1}$ called [the ${ }_{1}$ boy]'s mother

a. every TEAcher $\lambda_{2} t_{2}$ called [the $e_{2}$ teacher]'s $\mathrm{s}_{\mathrm{F}}$ mother

One selection of FA and FD from (44) that satisfies the focus licensing conditions is given in (45).

(45) a. $\mathrm{FA}=\lambda_{1} t_{1}$ called the $\mathrm{b}_{1}$ boy's mother 
b. $\quad \mathrm{FD}=\lambda_{2} t_{2}$ called $\left[\text { the }_{2} \text { teacher's }\right]_{\mathrm{F}}$ mother

c. $\quad \mathrm{FD}^{\prime}=\lambda_{2} t_{2}$ called $\left[\text { the }_{2} \text { boy's }\right]_{\mathrm{F}}$ mother

d. $\mathrm{FD}^{-}=\lambda_{2} t_{2}$ called the $\mathrm{e}_{2}$ teacher's mother

In particular, contrastiveness is satisfied because $\mathrm{FA}$ and $\mathrm{FD}^{-}$denote functions with different domains:

(46) $\quad$ a. $\quad \llbracket \mathrm{FA} \rrbracket=f$ where $f:\{x: \operatorname{teacher}(x)=1\} \mapsto\{0,1\}, \ldots$

b. $\llbracket \mathrm{FD}^{-} \rrbracket=g$ where $g:\{x: \operatorname{boy}(x)=1\} \mapsto\{0,1\}, \ldots$

Since the FA and FD considered in (45) contain the binders of the bound pronouns, it has been shown here that the new account predicts a difference in meaning between these constituents. This also explains why the use of adnominal however is licit.

\section{$3.2 \quad \bar{A}$-Traces and Pronouns Mean the Same}

One prediction of my proposal arises from what is known about traces. It has been argued that traces are syntactically and semantically definite descriptions, with unpronounced parts (Chomsky 1993, Fox 1999, Sauerland 1998).

Therefore, my proposal predicts that $\bar{A}$-traces should be able to license destressing of pronouns, as Danny Fox (p.c.) first pointed out to me. Moreover, this 
should depend on the lexical material in the $\bar{A}$-bar trace: The destressing of pronoun should be possible if and only if the antecedents are lexically the same (see also Section 3.4). This prediction is bourne out by (47) (after Fox, p.c.) and (48).

(47) a. I saw [every picture of every man who wanted me to see \#him/HIM today $]_{\mathrm{DP}_{1}}$.

b. I saw [every picture of every man who wanted me to see it/\#IT today $]_{\mathrm{DP}_{1}}$.

(48) a. Every student $\mathrm{i}_{\mathrm{i}}$ beat every teacher $\mathrm{j}_{\mathrm{j}}$ who expected that she $\mathrm{i}_{\mathrm{i}}$ would beat her $_{j}$

b. Every student ${ }_{i}$ beat every teacher ${ }_{j}$ who expected that $\mathrm{SHE}_{\mathrm{j}}$ would beat $\mathrm{HER}_{\mathrm{i}}$.

Consider the LF-representation of (48b) in (49). Since the example exhibits antecedent contained destressing, I assume that QR of the object is required. Therefore, the FA in (49) contains two traces, the trace of the subject and the QR trace of the object. These traces contrast with the two focussed pronouns in the FD.

(49) [every student] $\lambda_{1}$ [every teacher

$\left[\lambda_{2} t_{2}\right.$ expected that $\left[\text { the }_{1} \text { teacher }\right]_{\mathrm{F}}$ beat $\left.\left.\left[\mathrm{the}_{2} \text { student }\right]_{\mathrm{F}}\right]\right]$

$\lambda_{2} \underbrace{\left[\text { the }_{1} \text { student] beat [the }{ }_{2} \text { teacher] }\right.}$

FD

FA 


\subsection{Non-conservative Quantifiers}

Does the E-type representation of bound pronouns ever have an effect on the semantics? Consider again the two alternative representations proposed for bound pronouns in (50) with $Q$ being any quantifier. (50a) and (50b) don't in general have the same interpretation - the scope of $Q$ in (50b) presupposes teacher-hood.

(50) $Q$ teacher called his mother

a. $Q$ teacher $\lambda_{1} t_{1}$ called $x_{1}$ 's mother

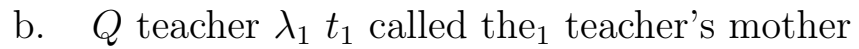

For conservative quantifiers $Q$, the presupposition of (50b) is always satisfied (cf. Fox 1999 on A-traces). With non-conservative quantifiers, however, representation (50b) should result in a presupposition failure.

I claim that the predicted effect can be demonstrated in examples with bound indexical pronouns. Kratzer (1998) (attributing the observation to Irene Heim, p.c.) first observed that examples with only show that indexicals in English can be bound. Consider the ambiguity of example (51): the two readings arise depending on whether the second occurrence of you is bound by the first or whether it's coreferent with it, but not bound.

(51) Only you brought something you like. 
a. Only you $\lambda_{1} t_{1}$ brought something $x_{1}$ liked (bound) entails: Nobody else brought something he likes.

b. Only you $\lambda_{1} t_{1}$ brought something you like (coreferent) entails: Nobody else brought something you like.

A similar ambiguity is found in (52) with the indexical $I$.

(52) Only I know when I arrived.

My argument is based on the new observation that (51) and (52) are disambiguated by focus. A focussed indexical cannot be bound, as shown by (53a). A destressed indexical, on the other hand, prefers the bound interpretation.

(53) a. Only YOU brought something YOU like. (coreferent, *bound)

b. Only YOU brought something you like. (bound, ?? coreferent)

Further evidence is provided in (54): In (54a), the bound reading is blocked by focus on you.

(54) Discourse: Everybody else likes all his colleagues.

a. Only YOU have colleagues you/\#YOU can't stand. 
Consider the representation in (56) with a bound E-type you, which is required for focus licensing ${ }^{4}$ - I assume here that you has an interpretation as a predicate true only of the person addressed.

Only you $\lambda_{1} t_{1}$ brought something [the ${ }_{1}$ you] like

Since $\left[\right.$ the $_{1}$ you $]$ presupposes that $g(1)=\llbracket$ you $\rrbracket$, the scope of the quantifier only you in (56) is a function with a singleton set as its domain-therefore, (55) is either trivially true or a presupposition failure. Intuitively, the sentence (53a) with focus on you is paraphrasable as the tautologous: Only you are you and brought something you like. Plausibly, this tautologous interpretation isn't considered available when judging (53a) and therefore only the coreferent interpretation is available. ${ }^{5}$

\footnotetext{
${ }^{4}$ The need for an E-type representation has only been demonstrated in cases where there's an antecedent with a bound pronoun in the parallel position around. The other alternative to consider is that there's an antecedent like (i) where the parallel position is occupied by some material other than a bound pronoun - if there's no antecedent parallel up to the focussed constituents, destressing of all the other material would not be licensed.

(i) (Only) John brought something Mary likes.

It's quite easy to see that when the index-insensitive focus licensing condition (29b) is adopted, the focus on the bound pronoun is required only on the E-type analysis. If the index-sensitive condition is adopted, the issue is more complicated. Under the assumption that then only the whole clause is considered as an FD, it follows that then, too, the focus is licensed only on the E-type analysis of the pronoun.

${ }^{5}$ Kratzer (1998:(23)) observes a similar interaction of focus and binding in the example (i). Her account, however, is very different from mine and doesn't extend to the examples in the text.
} 
(56) $\llbracket \lambda_{1} t_{1}$ brought something $\left[\right.$ the $_{1}$ you $]$ like $\rrbracket=f$ with

$f:\{y o u\} \mapsto\{1,0\}$

\subsection{Antecedent Effect}

More support for the claim that bound pronouns may have hidden content comes from the following observation: If the antecedents of the two bound pronouns are identical, the second pronoun cannot be focussed. (Thanks to Irene Heim (p.c.) for first hinting at data like (57).) This is illustrated in (57) and (58).

(57) Discourse: Did every boy call his mother?

a. \#Yes, every boy called HIS mother.

b. No, every TEAcher called HIS mother.

(58) Discourse: I didn't expect every teacher to get what she wanted.

a. \#But every teacher GOT what SHE wanted.

b. In the end, every GIRL got what SHE wanted.

(i) a. Only I answered a question that you didn't think I could answer. Nobody else answered a question you didn't think I could answer.

b. Only I answered a question that you didn't think i could answer. Nobody else answered a question you didn't think he could answer. 
This antecedent effect follows from the main proposal of this section. Consider the representations for (57) in (59).

(59) a. Every boy $\lambda_{1} t_{1}$ called the ${ }_{1}$ boy's mother

b. Every teacher $\lambda_{2} t_{2}$ called the $e_{2}$ teacher's mother

For the FA and FD in (60), which are analogous to the domains considered in the analysis of (44) above, contrastiveness is violated, because $\mathrm{FD}^{-}$and FA are identical in meaning.

(60) $\quad$ a. $\mathrm{FA}=\lambda_{1} t_{1}$ called the $\mathrm{f}_{1}$ boy's mother

b. $\quad \mathrm{FD}=\lambda_{2} t_{2}$ called $\left[\text { the }_{2} \text { boy's }\right]_{\mathrm{F}}$ mother

c. $\quad \mathrm{FD}^{\prime}=\lambda_{2} t_{2}$ called $\left[\text { the }_{2} \text { boy's }\right]_{\mathrm{F}}$ mother

d. $\quad \mathrm{FD}^{-}=\lambda_{2} t_{2}$ called the $\mathrm{e}_{2}$ boy's mother $\Longrightarrow \llbracket \mathrm{FD}^{-} \rrbracket=\llbracket \mathrm{FA} \rrbracket$

The demonstration that the focus licensing condition isn't satisfied for a particular choice of FA and FD is of course not sufficient to explain the impossibility of focus: it needs to be shown that for every permissible choice of FA and FD, the focus licensing condition isn't satisfied. In particular, the question is whether a choice of FA and FD that don't include the binder would incorrectly license the focus in (57) and (58) when different indices are used as in the representations in (59). At this point, I see two ways to block this prediction: Either the index-insensitive focus licensing condition (29b) is adopted, or there's a condition that excludes the FDs that don't exclude 
the antecedent from consideration. If either of these routes is chosen, the antecedent effect follows from the new proposal.

The antecedent effect allows us to determine more precisely the question of what the content of the bound pronoun may be. Consider the following cases.

Different extensions: As Orin Percus (p.c.) first pointed out to me, sometimes it's sufficient that the extensions of the two antecedent restrictors differ to license focus on a bound pronoun.

(61) Discourse: Did every flight leave at the time it was scheduled for on Tuesday?

a. All I know is that, on Wednesday, every flight left at the time IT was scheduled for.

This observation shows that in these cases the bound variable pronoun cannot just have as its content the restrictor of its antecedent since these are identical in (61) and therefore couldn't license the focus. Rather, in these cases the content of the bound pronouns seems to be flight on Tuesday contrasting with flight on Wednesday.

A possibly related observation was made independently by Orin Percus (p.c.) and Dimitriadis (2001). They note that examples like (62) are acceptable only if John and his brother have different mothers.

(62) John called his mother and John's BROTHER called HIS mother. 
This effect seems to be specific to possessives. An explanation of it could be to assume that the apparent focus on his in (62) is actually a focus on the entire DP his mother (cf. Krifka (1998)), and that all referential DPs, not just pronouns may have presuppositional content (see also example (70) below).

Different quantifiers: Does the quantifier of the antecedent matter for the focussability of a bound pronoun? In the following examples, at least the quantifier seems to be not relevant, as predicted. ${ }^{6}$

(63) Discourse: I expected no student to call his mother.
a. But EVERY student called his/\#HIS mother.
b. But at least one student called his/\#HIS mother.

(64) Discourse: Did every student call his mother?

a. No, NO student called his/\#HIS mother.

b. All I know is that at least one student called his/\#HIS mother.

\footnotetext{
${ }^{6}$ It remains to be seen whether all examples behave as predicted. Consider (i) which was provided by an anonymous reviewer.

(i) Discourse: Almost every contestant used a battery to power his car.

a. One Japanese contestant, however, used a match to power HIS car.

In this case, the contrast might be based on the content this Japanese contestant contrasting with the contestant different from this one Japanese contestant. However, it's difficult to see how this goes together with the semantics of almost.
} 
Overlap: Is the antecedent effect observed if the restrictors of the two antecedent quantifiers overlap? It seems that focus is licit in case of overlap ((65b)) unless a sub- or superset relation ((65a) and (66a)) holds. However, the judgements are quite subtle.

(65) Discourse: Did every young student call his mother?

a. In fact/No, EVery student called his/\#HIS mother.

b. All I know is that every BLOND student called his/HIS mother.

(66) Discourse: Did every student call his mother?

a. All I know is that every YOUNG student called his/\#HIS mother.

Definitely the effect in (66) is expected because it's well established that entailments from the preceding discourse can license focus and destressing (Tancredi 1992). Sometimes this is called Implicational Bridging. In (66), the discourse entails the question Did every young student call his mother, and therefore the example is expected to exhibit the antecedent effect.

\subsection{Classical E-type Pronouns and Focus}

The proposal that pronouns have descriptive content that is interpreted as a presupposition is, of course, not new: Evans (1977) proposes that there is a class of pronouns, 
E-type pronouns, that are semantically definite descriptions. New, however, is my proposal that even bound variable pronouns can be E-type pronouns.

I believe that the two proposals are closely related, though the lines of argumentation are different: The classical evidence for the E-type analysis of pronouns comes solely from the available interpretations of sentences with pronouns. For example, Evans and others argue that on the salient interpretations of (67a) and (67b) they must be analyzed as a definite description: The pronoun they in (67a) might be understood as the congressmen that voted for the bill and the pronoun it in (67b) as the donkey he owns.

(67) a. Few congressmen voted for the bill. They were very junior.

b. Every farmer who owns a donkey beats it.

Since I have argued that focus provides evidence for an E-type analysis of bound variable pronouns, it is natural to ask the following: Does focus also provide evidence for the E-type analysis of such bona fide E-type pronouns as those in (67)? Indeed, this is the case, as (68) shows.

(68) a. Few congressmen voted for the bill and they were very junior, but most SENATORS voted for the bill and THEY were all SENIOR.

b. Every farmer who owns a donkey beats it, but every farmer who owns a HORSE beats IT. 
In both examples, there's a second pronoun that receives contrastive focus. I propose that the two E-type pronouns are contrasted with each other and that the contrast is due to the content of the two pronouns. The second occurrence of they in (68) would be analyzed as the senators who voted for the bill and therefore contrast with the first occurrence of they, which is understood as the congressman who voted for the bill. Similarly, the focussed it in (68b), if understood as the horse he owns, contrasts with the donkey he owns.

At this point, a further, more ambitious prediction my analysis makes comes to mind. Namely, the prediction that contrastive focus on an E-type pronoun should be obligatory in examples like (68). Indeed, this prediction is borne out in (68a).

Donkey anaphora, as in (68b), however, don't seem to bear out this further prediction. On closer consideration, though, the behavior of donkey anaphora comes as no surprise. Over the last 25 years, various semantic mechanisms have been developed and independently motivated that account for donkey anaphora with less content in the relevant pronoun than Evans' original proposal (cf. Chierchia 1995 Heim 1990, Elbourne 2001, Lin 1996, Kadmon (1987)). For example, the pronouns in (68b) could possibly be understood as the same definite description, the animal he owns, as in the paraphrase (69).

(69) Every farmer who owns a donkey beats the animal he owns, and every farmer who owns a HORSE beats the animal he owns. 
I believe that the study of focus in this context can help to determine what precisely the content of the pronoun is. In Sauerland (2000), I presented several examples where, in my judgement and those of my informants, the focus does seem to be obligatory. However, a full discussion of further predictions concerning donkey anaphora is beyond the scope of the present paper.

\section{$4 \quad$ Ellipsis?}

In the previous section, I argued that in addition to the classical cases of E-type pronouns, bound variable pronouns too can be E-type pronouns. Semantically, Etype pronouns are analyzed as having some silent content that is presupposed of the referent of the pronoun. I have shown that focus can indicate what this silent content may be. In this section, I want to address the question of how this silent content of the pronoun is represented.

For classical E-type pronouns, two proposals have been made for the representation of the silent content. Evans $(1977,1980)$ proposes that the content of the pronoun is syntactically represented and, in fact, develops LF-copying rules to account for this. While Evans himself doesn't explicitly draw a parallel between these rules and VP-ellipsis, Heim (1990) and Elbourne (2001) develop his proposal in this direction. Cooper (1979), on the other hand, proposes that the content of E-type 
pronouns doesn't have such an explicit syntactic representation, but rather is a silent relation variable inherent to the pronoun (see also Heim and Kratzer 1998).

In this section, I argue that the facts with bound variable, E-type pronouns provide evidence in favor of Cooper's proposal. I present two arguments, the first of which is that focus licensing doesn't follow straightforwardly from the ellipsis analysis since in corresponding examples with VP-ellipsis focus isn't licensed. The second argument is that in some cases an analysis in terms of ellipsis seems to be impossible since there's no available antecedent.

Neither of these arguments, of course, fail to rule out that there's also some elided content in pronouns in some cases. In fact, we find facts similar t those with bound pronouns with definite determiners in German, which must receive an analysis involving NP-ellipsis, as Wiltschko (1998) argues. For cases like (70), I therefore assume that the definite determiners have the elided NP-complements Jungen and Mann, but also have Cooper's inherent relation argument and that it's the latter that account for the contrast.

(70) Ein Bruder jedes Jungen hat den angerufen und ein Bruder jedes a brother every boy has the called and a brother every MANNES hat DEN/den angerufen. man has the called. 
DRAFT

\subsection{Focus Placement}

Consider first the argument from the placement of focus. Schwarzschild (1999) argues that focus must be placed on the smallest constituent possible. For example, focus on part $A$ of a phrase $[A B]$ is preferred over focus on the entire phrase. This, however, raises a problem for the proposal that the content of an E-type pronoun is represented syntactically: on this analysis, the structure of the pronoun would be [pronoun NP], where NP is different from the antecedent. Therefore, focus should be placed on the elided NP rather than on the pronoun or the entire phrase.

One might think of slight modifications to Schwarzschild's proposal, to rescue the ellipsis proposal. However, Schwarzschild's proposal makes exactly the right prediction for VP-ellipsis, as shown by the contrast in (71). The elided material is enclosed in angular brackets.

(71) a. When I talk, you say I shouldn't $\langle$ talk $\rangle$, and when I keep quiet, you also say I shouldn’t〈keep quiet〉.

b. \#When I talk, you say I shouldn't $\langle$ talk $\rangle$, and when I keep quiet, on the other hand, you say I SHOULDn't 〈keep quiet〉.

The examples in (71) are of a type first discussed by Schwarz (1999): an elided VP appears in a corresponding position to another elided VP with different content. 
Hence, the examples in (71) are exactly analogous in structure to the ellipsis analysis of pronouns, which is exemplified in (72).

(72) Every boy called his 〈boy mother, every TEACHER called HIS 〈teacher〉 mother.

However, VP-ellipsis in (71) doesn't allow focus on the head that takes the elided complement. This is expected on Schwarzschild's analysis because the elided VP is assumed to have internal constituent structure, and a focus on the constituent shouldn't 〈keep quiet〉 is, therefore, not placed on the smallest constituent possible. Rather, the focus should be placed on the constituent $\langle k e e p$ quiet $\rangle$, and indeed we find this focus obligatorily when the elided VP is pronounced:

(73) When I talk, you say I shouldn`t talk, and when I keep QUIET, on the other hand, you say I shouldn't keep QUIET.

In fact, examples with bona fide NP-ellipsis behave just like VP-ellipsis. Consider, for example, (74).

(74) When many boys play, one $\langle$ boy $\rangle$ ends up crying. When many GIRLS play, however, ONE 〈girl〉 ends up crying.

The ellipsis structure (72) could not explain the focus found on bound variable pronouns unless some explanation was found for the difference between this case and VP-ellipsis in (71) and NP-ellipsis in (74). 
DRAFT

\subsection{Bound Pronouns in the Restrictor}

A second problem for the ellipsis analysis was brought to my attention by Pauline Jacobson (p.c.). She provided me with the example (75), which allows the bound variable pronoun his in the second relative clause to receive contrastive focus.

(75) Every man who loves his mother talked to every man who HATES HIS mother.

The focus in (75) must be licensed by a contrast with the bound pronoun in the first relative clause. For example, we might analyze the two pronouns as having the content the man who loves his mother contrasting with the man who hates his mother to explain the focus in (75).

In contrast to the examples in section 1 and elsewhere, however, the bound pronouns in (75) both occur in the restrictor of a quantifier. Moreover, the contrast between the two is established only by other material in the relative clauses that the pronouns themselves occur in. Therefore, a ellipsis account of (75) faces the problem of antecedent containment: the plausible antecedent for ellipsis licensing man who hates his mother contains the putative ellipsis site, the pronoun his.

Antecedent containment is known to occur in the case of VP-ellipsis as well (Sag 1976 and others), and there it has been seen that covert movement (e.g. Larson and May 1990) or string-vacuous movement (e.g. Fox 2000) resolves antecedent containment (cf. Jacobson paper in this volume). An analogous treatment of (75), 
however, seems hard to swallow: the proposal would be that the pronoun his moves to adjoin to the NP man who loves/hates $x$ 's mother. In example (76), a similar movement analysis would even have to cross two relative clause boundaries.

(76) Every man who found a girl who loved his mother talked to every man who found a girl who HATED HIS mother.

By contrast, it is well established that the resolution of antecedent containment in VPellipsis is subject to strong locality constraints (e.g. Jacobson paper in this volume and references there). This further difference between VP-ellipsis and the silent content of pronouns hence provides another argument against an ellipsis analysis of the latter.

\section{Conclusion}

In this paper, I have postulated four new theses concerning pronouns, in particular bound variable pronouns. The structure of the paper has been layered in the following

sense: I started with the most basic and least controversial thesis. I then argued based on the already established thesis in the following section for a more specific thesis. One benefit of this structure is that even if the reasoning that has led me to a more specific thesis in a later section were shown to be wrong, still the more basic theses established up to that point would still be supported. Consider now each of the theses of my argument sequence. 
Thesis one is that bound variable pronouns can differ in their interpretation. My evidence for this assumption has come from facts like (77), where the bound pronoun seems to bear contrastive focus.

Every boy called his mother. Every teacher, however, called HIS mother.

This result is interesting because it argues against the proposal of Jacobson (1999) and others that bound variable pronouns always denote the identity function. Furthermore, the result can be applied as a test for whether a phrase is interpreted as a bound variable.

Thesis two is that bound variable pronouns can cause a difference in meaning even for constituents in which they are bound. The argument I presentedfor this thesis in section 2 was based on the licensing of however in (77). Assuming that however takes two arguments, as shown in (78) and is licit only if both arguments differ in meaning from the relevant antecedent, the thesis follows.

(78) however (every teacher) ( $\lambda x x$ called $\mathrm{HIS}_{x}$ mother)

This result is important because it establishes that differences in indexation alone are insufficient to account for the contrastiveness of bound variable pronouns.

Thesis three is that bound variable pronouns can have presuppositional content. This proposal accounts for the licensing of however in (78) because its argument 
would be analyzed as (79), which is a function that has as its domain the set of teachers, while the antecedent denotes a function that has the set of boys as its domain.

(79) $\lambda x x$ called [the teacher $x$ ]'s mother.

In section 3, I gave three additional arguments for this analysis: cases where bound

pronouns and $\bar{A}$-traces mean the same, the analysis of variables bound by nonconservative quantifiers, and the effect the antecedent has on whether focus on a bound variable is possible or not.

Thesis four is that the presuppositional content is a silent property variable internal to the pronoun, similar to the resource domain variables in work on quantifiers, and as proposed for classical E-type pronouns by Cooper (1979). My arguments for this claim argued against one other conceivable analysis, namely in terms of ellipsis of an NP. I showed that this putative NP-ellipsis behaves differently from VP-ellipsis with respect to focus placement and antecedent containment. The account in terms of a silent property variable faces none of these problems, and should therefore be preferred.

\section{References}

Büring, Daniel. 1995. The great scope inversion conspiracy. In Proceedings of SALT 5, ed. by M. Simons and T. Galloway, 37-53. Cornell, CLC Publications. 
Chierchia, Gennaro. 1995. Dynamics of meaning. University of Chicago Press.

Chomsky, Noam. 1993. A minimalist program for linguistic theory. In The View from Building 20, Essays in Linguistics in Honor of Sylvain Bromberger, ed. by K. Hale and J. Keyser, 1-52. MIT Press.

Cooper, Robin. 1979. The interpretation of pronouns. In Selections from the Third Groningen Round Table, Syntax and Semantics, Volume 10, ed. by F. Heny and H. Schnelle, 61-92. New York: Academic Press.

Dimitriadis, Alexis. 2001. Function domains in variable free semantics. In Proceedings of SALT 11. Ithaca, N.Y., CLC Publications, Cornell University. (to appear).

Elbourne, Paul. 2001. E-type anaphora as NP-deletion. Natural Language Semantics $9.241-288$.

Evans, Gareth. 1977. Pronouns, quantifiers, and relative clauses, I \& II. The Canadian Journal of Philosophy 7.467-536, 777-797.

—. 1980. Pronouns. Linguistic Inquiry 11.337-362.

Fox, Danny. 1999. Reconstruction, variable binding and the interpretation of chains. Linguistic Inquiry 30.157-196.

—. 2000. Antecedent contained deletion and the copy theory of movement. Manuscript, Harvard University, Cambridge, Mass.

Frege, Gottlob. 1879. Begriffsschrift. Eine der arithmetischen nachgebildete Formelsprache des reinen Denkens. Halle, Germany: Neubert. 
Heim, Irene. 1983. On the projection problem for presuppositions. In Proceedings of WCCFL 2, ed. by D. Flickinger, 114-125. Stanford, Calif., CSLI.

—. 1990. E-type pronouns and donkey-anaphora. Linguistics and Philosophy $13.137-177$.

—- and Angelika Kratzer. 1998. Semantics in Generative Grammar. Oxford: Blackwell.

Hirschberg, Julia, and Gregory Ward. 1991. Accent and bound anaphora. Cognitive Linguistics 2.101-121.

Jacobson, Pauline. 1999. Towards a variable-free semantics. Linguistics and Philosophy $22.117-184$.

- 2000. Paychecks, stress, and variable free semantics. In Proceedings of SALT 10, ??-?? Ithaca, N.Y., CLC Publications, Cornell University.

Kadmon, Nirit. 1987. On unique and non-unique reference and asymmetric quantification. Ph.D. dissertation, University of Massachusetts, Amherst.

Kratzer, Angelika. 1998. More structural analogies between pronouns and tenses. In Proceedings of SALT 8, 92-110. Ithaca, N.Y., CLC Publications.

Krifka, Manfred. 1998. Focus ??? Proceedings of ESSLLII.

Larson, Richard K., and Robert May. 1990. Antecedent containment or vacuous movement: Reply to Baltin. Linguistic Inquiry 21.103-122.

Lin, Jo-Wang. 1996. Polarity licensing and wh-phrase quantification in Chinese. 
DRAFT

Ph.D. dissertation, University of Massachusetts, Amherst.

Reinhart, Tanya, and Eric Reuland. 1993. Reflexivity. Linguistic Inquiry 24.657-720.

Roberts, Craige. 1991. Distributivity \& reciprocal distributivity. In Proceedings of SALT I, 209-229. Ithaca, Cornell University.

Rooth, Mats. 1992a. A theory of focus interpretation. Natural Language Semantics $1.75-116$.

- 1992b. Ellipsis redundancy and reduction redundancy. In Proceedings of the Stuttgart Ellipsis Workshop, ed. by S. Berman and A. Hestvik. Arbeitspapiere des Sonderforschungsbereichs 340, Bericht Nr. 29, IBM Germany, Heidelberg.

Sag, Ivan. 1976. Deletion and logical form. Ph.D. dissertation, Massachusetts Institute of Technology, Cambridge, Mass.

Sauerland, Uli. 1998. The meaning of chains. Ph.D. dissertation, Massachusetts Institute of Technology, Cambridge, Mass.

—. 1999. Why variables? In Proceedings of NELS 29, ed. by P. Tamanji, M. Hirotani, and N. Hall, 323-337. Amherst, Mass., GLSA.

—. 2000. The content of pronouns: Evidence from focus. In The Proceedings of SALT 10, ed. by T. Matthews and B. Jackson. Ithaca, N.Y., Cornell University, CLC Publications. to appear.

Schwarz, Bernhard. 1999. Topics in ellipsis. Ph.D. dissertation, University of Massachusetts, Amherst. 
Schwarzschild, Roger. 1999. Givenness, AvoidF and other constraints on the placement of accents. Natural Language Semantics 7.141-177.

Soames, Scott. 1989. Presupposition. In Handbook of Philosophical Logic, vol. IV, ed. by D. Gabbay and F. Guenthner, 553-616. Dordrecht, Netherlands: Reidel.

Tancredi, Christopher. 1992. Deletion, deaccenting and presupposition. Ph.D. dissertation, Massachusetts Institute of Technology, Cambridge, Mass.

Wiltschko, Martina. 1998. On the syntax and semantics of (relative) pronouns and determiners. Journal of Comparative Germanic Linguistics 2.143-181. 